\title{
ELICITING USER REQUIREMENTS FOR CRITICAL COMMUNICATIONS IN PUBLIC SAFETY USING ACTIVITY THEORY AND SYSTEMISM
}

\author{
Débora Vanessa Campos Freire ${ }^{1}$, Alessandra Callado Bezerra de Mello² and Ana Clara Cândido ${ }^{1}$ \\ ${ }^{1}$ Federal University of Santa Catarina, Brazil \\ ${ }^{2}$ Federal University of Pernambuco, Brazil
}

\begin{abstract}
The decision to adopt a technology is a problem that includes different aspects of information. This view, considering not only the technical aspects, but also economic factors and social context, is the definition of Technological Assessment (TA). This work is an applied exploratory research based on primary and secondary data. It focuses on user requirements capture based on understanding the activity system's context and user-related task analysis as a resource for developing or adjusting the Critical Communication (CC) systems used in Public Safety (PS). The collected was analyzed data with the worldview of Systemism, which considers that everything is either a system or a component of a system, and every system has peculiar properties. This work also proposes a system characterized by their mechanism, using the construction logic of Composition-Environment-Structure-Mechanism (CESM) to represent the problem. Starting from a theoretical framework regarding resource information on Activity Theory (AT) and Usability, in order to identify methods of data collection for generating information on user requirements, and Systemism in order to build a System, this work aims to improve Human Computer Interaction (HCI) design through user requirements to support the development or improvement of a computer system regarding the activities developed by CC users in the field of Public Safety.
\end{abstract}

\section{KEYWORDS}

User Requirements, Activity Theory, Systemism, Critical Communication, Information Science, Public Safety

\section{USER REQUIREMENTS}

Solutions for informational problems cannot be developed isolated from other actors and mechanisms of the ecological chain. As a rule, they require the consideration of several other actors and mechanisms in the larger set of informational ecology (SARACEVIC, 1996). According to Leventhal \& Barnes (2008), in Software Engineering, a computerized solution is required in order to solve a system or process problem, while, in Usability, the user context and its tasks are the focus of the problem. Usability considers the actors are the users of the system. The incorporation of AT in HCI design aims to include the user's context in social, cultural and psychological aspects, helping the understanding of human activities related to the problems and focusing on the actors involved, being these subjects and members of the system (MELLO \& NEVES, 2018). Regarding the construction of a broad representation, Systemism is related to information concepts, seeking a better understanding of the system, its actors, processes, environment and relationships between them. Both AT and Usability have elements that are deeply related to Systemism, and therefore can be used together in order to capture user requirements and build a system representation.

\section{INFORMATION SCIENCE, USABILITY, ACTIVITY THEORY AND SYSTEMISM}

Although there are various definitions of the term 'information', this study appropriates the concepts consolidated in the field of Information Science. According to Buckland (1991), 3 meanings can be identified: information as a process, as knowledge and as a thing. In this context, the tools used in CC activities - for 
example, radio equipment - are information, and they can be categorized as “information-as-thing", assuming that they will be an object of analysis. Radio interfaces should be built in such way that allows the user to use the device efficiently, effectively and satisfactorily; therefore, interfaces can be understood as "information-as-process". User perception can be understood as "information-as-knowledge", or what is perceived from the information-as-process that can be measured through the application of usability and user experience.

Performing a task using a product or system can be challenging; what will make this task easier or not is the relationship between user and system. According to Jordan (1998), usability should not be considered isolated from other factors, since it's a property of the interaction between product, user and environment. Usability addresses this relationship, being a determining factor for user satisfaction over various consumer products. According to Falcão \& Soares (2013), consumer products are predominantly three-dimensional objects, used in a determined environment, that have gone through the project conception and development for industrial manufacturing. Radio equipment is one of the tools that can be analyzed within this definition. Different radio models provide different functionalities and interfaces; thus, users must have a wide range of options, focused not only on the product, but also on improving efficiency and effectiveness in PS actions.

In order to understand the problem, the adopted strategies consider user requirements as a basis information. The first step for a system's design and construction is to collect data. For this, this work used an activity analysis, based on AT, that considers that activities are developed through action (conscious) and operations (unconscious), while individuals interact with the activity's environment considering social relations. Mwanza (2001) proposed a methodology that guides the process of data collection and interpretation of requirements, using Engeström System Model of Activities (1987) as a heuristic model. The method makes possible the analysis of activities and the understanding of the community's social and cultural context, considering aspects of mediation through tools, rules and division of labor.

The process of operationalization is applied in 6 stages: modeling of the situation; production of the activity system; decomposition of the activity system; generation of research questions; conducting of detailed research; and interpretation of the findings. From the interviews, it was possible to identify components and produce the Activity System. Mello \& Neves (2018) present an adaptation of the Mwanza (2001) method, proposing a hexagonal diagram representation system based on Amstel (2010), instead of the second-generation diagram of Engeström (1987). The authors propose a Canvas diagram, named "Canvas Activity Analysis". Through the understanding of the activity with the identification of its components and the relations between them, this method can contribute as a subsidy for TA in CC for Public Safety.

For a broader system view, this paper uses Systemism concepts from Bunge (2000, 2005). Bunge opposes approaches that are too reductionist, reducing what should be irreducible; the author proposes the CESM model, which describes a system at a certain level of its composition. Each Component is an atom of the system; the Environment are the external items that act upon or suffer action from a component; its Structure are the connections between components and between those and the environment; and the Mechanism are the processes that act on transformations, causing, for example, the growth or collapse of a system. The epistemology adopted by Bunge is scientific realism, with Systemism as the ontological foundation. The systemic approach could be summarized in 7 general rules: put all social facts into a broader context; divide each system into its composition, environment and structure; distinguish the system's various levels and display their relationships; seek the mechanisms; verify the hypothesis by experimental manipulation; prefer dynamic hypothesis to phenomenological models; in case of system mal function, check the C, E, S, M (SILVA, 2016).

\section{METHODS}

The present work is an applied research, characterized as exploratory and descriptive, using quantitative and qualitative approaches. Secondary data were obtained through a Systematic Review of Literature and bibliographical review. Primary data were obtained from interviews and data treatment based on Mwanza (2001) and Mello \& Neves (2018), applied to 10 system users who were also experts from industry, PS agencies and the Ministry of Science, Technology and Innovation of Brazil. This work aims to represent, through the interviews' answers, the perception of specialists, society members, technical teams, users, government and manufacture companies. The CESM representation also allows the visualization of the innovation ecosystem. 


\section{EXPERIMENT APPLICATION}

This research applied stages 1 and 2 of the Mwanza (2001) method with contributions from Mello and Neves (2018), in order to understand the components and the context of the activity. The questions applied were: 1. How would you describe CC activity? 2. What is the purpose of CC? 3. Who is involved in CC? 4. What resources are used for $\mathrm{CC}$ ? 5. What are the social norms, rules or regulations that influence or govern the performance of CC? 6. What is the role of each individual in $\mathrm{CC}$ and how do they organize themselves? 7. What is the environment in which CC is carried out? 8. What is the desired result when performing CC? 9. If you could solve any aspect related to the activity, what would it be? In addition, we proposed other questions to the model, in order to assist in the elucidation of difficulties encountered in the activities system: 10 . What are the main difficulties you identify in the current CC scenario in Brazil? 11. What opportunities do you perceive in the advancement of technologies for CC in Brazil and in the possibility of partnerships with other countries? 12. What legal, economic and social implications do you consider relevant for this decision to implement new technologies for CC? 13. What is your opinion on the possibility of interoperability between Public Safety organizations, using technologies in LMR and LTE? 14. In your opinion, which would be an ideal model for CC in Brazil, considering current and future technologies?

\section{CANVAS OF CRITICAL COMMUNICATION'S ACTIVITY SYSTEM}

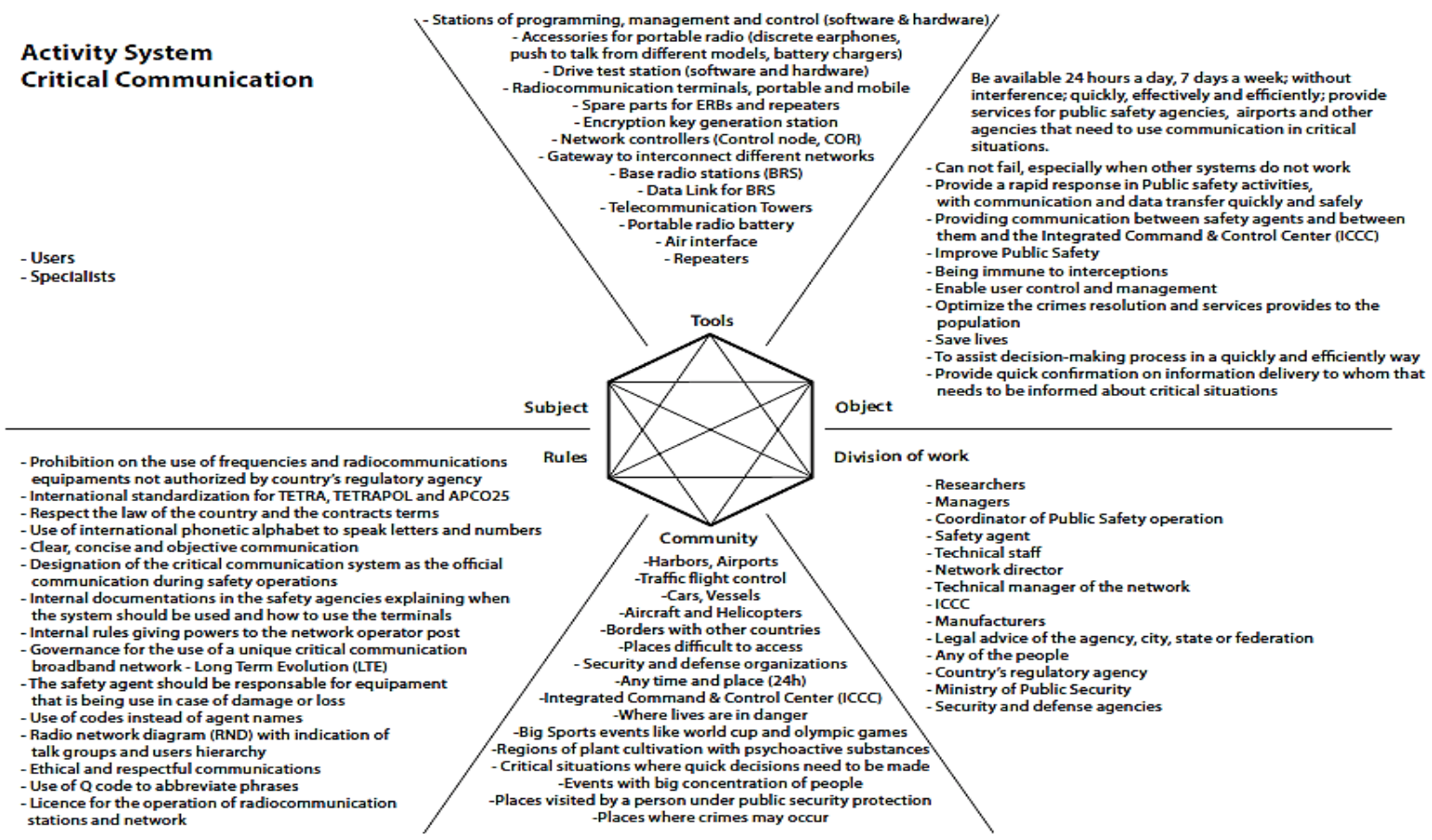

Figure 1. Critical Communication's Activity System, based on the Diagram from Mello \& Neves (2018)

With the canvas, one can identify, for example, the governmental institutions and their respective actions that make possible for the actors to execute the objective of the activity. 


\section{SYSTEM CONSTRUCTION}

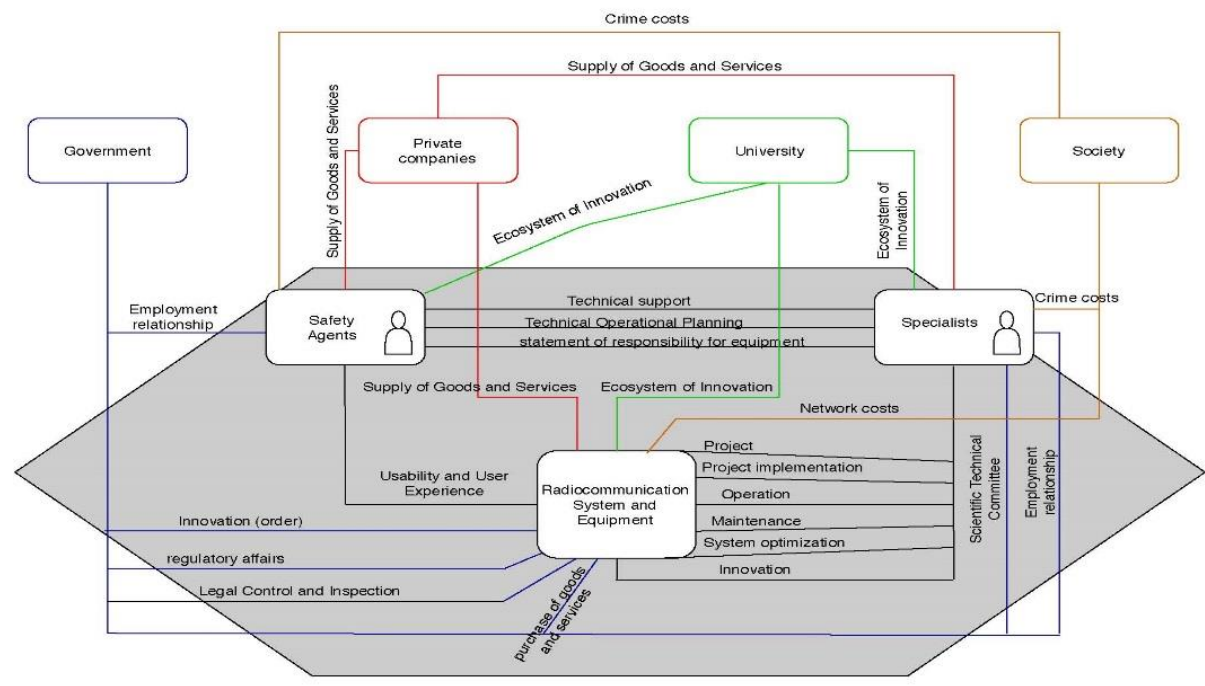

Figure 2. Critical Communication's System based on Critical Communication's Activity System and CESM concept

\section{CONCLUSION}

The results above present data that helps identifying, in the context of the organization, the actors, the means and the purpose of the activity. The "rules", "community" and "division of labor" fields provide important elements for understanding which entities may be relevant for creating an innovation ecosystem. The "tools" section enables a look over possible target elements for innovation. This work applied methods to collect user requirements that assist in a Technological Assessment exercise of Critical Communication in Public Safety, through the analysis of the Activity System and considering user requirements as a basis.

\section{REFERENCES}

Amstel, F. M. C. van., 2010. Interaction Design Yearbook. Faber-Ludens Institute for Interaction Design.

Buckland, M. K., 1991. Information as thing. American Society for Information Science, v. 42, n. 5, p. 351 - 360.

Bunge, M., 2000. Systemism: the alternative to individualism and holism. Journal of Socio-Economics, v. 29, n.2, p. $147-157$.

Bunge, M., 2005.Diccionario de filosofía. 3. ed. Buenos Aires: Siglo XXI.

Engeström, Y., 1987. Learning by Expanding: An Activity Theoretical Approach to Developmental Research. Helsinki: Orienta-Konsultit.

Falcão, C. S; Soares, M. M., 2013. Usability of Consumer Products: an analysis of the concepts, methods and applications. Estudos em Design, Rio de Janeiro, v. 21, n. 2.

Jordan, P. W., 1998. An Introduction to Usability. London: Taylor \& Francis.

Leventhal, Laura; Barnes, Julie, 2008. Usability Engineering: Process, Products and Examples. Pearson Education, Inc., New Jersey.

Mello, A. C. B. De; Neves, A. M. M. das, 2018. Eliciting Requirements for Digital Systems Using Activity and Task Analysis. In: (IADIS), I. A. for Development of the I. S. (Ed.). Multi Conference on Computer Science and Information Systems. Madrid: IADIS Press, p. 329 - 333. ISBN 978-989-8533-79-1.

Mwanza, D., 2001. Where Theory meets Practice: A Case for an Activity Theory based Methodology to guide Computer System Design. In: HIROSE, M. (Ed.). Proceedings of INTERACT'2001: Eighth ifip tc 13 international conference on human-computer interaction. Tokyo, Japan: IOS Press Oxford, UK.

Saracevic, T., 1996. Information Science: origin, evolution and relations. Perspec. Ci. Inf., Belo Horizonte, Brazil, v. 1, n. 1 , p. $41-62$.

Silva, L. M., Vianna, W. B., \& Kern, V. M. (2016, mai/ago.). O sistemismo de Bunge como base teórico-metodológica para pesquisa em Ciência da Informação. Em Questão, 22(2), 140 - 164. 